\title{
Impact Assessment of Different Polymers on Physicochemical Properties of Ibuprofen Loaded Solid Dispersions
}

\author{
Sonia Ferdousy ${ }^{1}$, B.K. Sajeeb ${ }^{1}$, Shahida Yeasmin ${ }^{2}$ and A.B.M. Faroque ${ }^{1}$ \\ ${ }^{1}$ Department of Pharmaceutical Technology, Faculty of Pharmacy, University of Dhaka \\ Dhaka-1000, Bangladesh \\ ${ }^{2}$ Department of Pharmacy, Mawlana Bhashani Science and Technology University, Santosh \\ Tangail-1902, Bangladesh
}

(Received: June 5, 2018; Accepted: July 24, 2018; Published (web): December 10, 2018)

\begin{abstract}
In the present study, solid dispersions of ibuprofen were prepared to improve aqueous solubility of ibuprofen. A series of formulations were prepared where PEG 6000 with polymers named PVP K30, cross PVP, poloxamer 237, HPMC ASLF, pregelatinized starch, Na-CMC, Eudragit L100, and kollidon IR were used in different ratios. Among 41 formulations, solid dispersions of ibuprofen in PEG 6000 with each of PVP K30, poloxamer 237, and Na-CMC at ratio of 2:9:7 revealed improved solubility of $952.73 \pm 1.31,878.18 \pm 0.97$, and $1263.64 \pm 1.58 \mu \mathrm{g} / \mathrm{ml}$, respectively. The physicochemical properties of these preparations were ascertained by FTIR, SEM, DSC, and particle size analyses. FTIR spectrum showed absence of chemical interactions and physical compatibilities between ibuprofen and polymers were confirmed by DSC. Disappearance of individual surface properties in solid dispersions were revealed by SEM studies, which indicated the formation of effective preparations. On the other hand, particle size analysis showed reduction in particle size of ibuprofen from solid dispersions that demonstrated solubility enhancement of ibuprofen. The above studies suggested that solid dispersions of ibuprofen in PEG 6000 at ratios of 2:9:7 with each of PVP K30, poloxamer 237, and Na-CMC were found to be effective to improve aqueous solubility.
\end{abstract}

Key words: Ibuprofen, poloxamer 237, PEG 6000, Na-CMC, particle size analyses, saturation solubility.

\section{INTRODUCTION}

Solid dispersion is an established technique to improve solubility of poorly aqueous soluble drugs. ${ }^{1}$ This technique disperses crystalline drugs in hydrophilic carriers as amorphous form and the dispersed drugs may achieve maximum level of particle size reduction after drying. ${ }^{2,3}$ Several techniques of solid dispersion named hot melt, electrostatic, inclusion complexes, and melting solvent methods, etc are used to improve solubility of poorly aqueous soluble drugs. ${ }^{4}$ Among these, hot melt and electrostatic methods are limited to heat stable drugs and inclusion complex is only suitable

Correspondence to: A B M Faroque

Email: abmfaroque@yahoo.com

Dhaka Univ. J. Pharm. Sci. 17(2): 183-190, 2018 (December) DOI: http://dx.doi.org/10.3329/dujps.v17i2.39174 for those that form complexes with cyclodextrin or calixerene. $^{5,6}$ On the other hand, melting solvent method can be used for heat sensitive drugs as well as for those drugs which can't form complexes. ${ }^{7}$ By appropriate control of shear rate and temperature, this method can disperse maximum amount of drugs in molten hydrophilic carriers. ${ }^{8}$

Commonly used non steroidal anti-inflammatory drug, ibuprofen has poor aqueous solubility and high permeability through gastric membrane. ${ }^{9}$ Thus, dissolution becomes rate limiting step and rapid dissolution of drug in gastric fluid is desirable for maximum bioavailability. ${ }^{10}$ But, ibuprofen is a heat sensitive drug which is unstable at $75^{\circ} \mathrm{C}$ temperature and can't form complexes with cyclodextrin or calixerene. ${ }^{11}$ So, melting solvent method can be 
applicable for solid dispersions of ibuprofen to improve solubility rate in gastric fluid. ${ }^{12,13}$ Polyethylene glycols (PEGs) are hydrophilic polymers and extensively used as carrier in solid dispersion preparations for their wetting, solubilizing, and surface active properties. ${ }^{14}$ Molten PEGs forms eutectic mixture with ibuprofen that belong to a category which exhibits complete miscibility in the liquid state and complete immiscibility with reduced particle size in the solid state. ${ }^{15}$ After solidification, ibuprofen separated from PEGs with reduced particle size, thus improves dissolution rate as well as absorption through gastrointestinal tract. ${ }^{16}$ Along with PEGs, different grades of polymers like polyvinyl pyrrolidone (PVP), poloxamers, and sodium carboxymethyl cellulose (Na-CMC) can be used to improve solubility profile of ibuprofen. ${ }^{17}$

In the recent study, solid dispersions of ibuprofen in PEG 6000 hydrophilic carrier were formulated by melting solvent method. The effects of polymers like PVP K30, poloxamer 237, and Na$\mathrm{CMC}$ in solid dispersion preparations were characterized by FTIR, SEM, DSC, and particle size analyzer. The present study has revealed an additional approach to enhance solubility of ibuprofen by preparing solid dispersions with polymers employing melting solvent method.

\section{MATERIALS AND METHODS}

Ibuprofen was gifted by Beximco Pharmaceuticals Limited, Bangladesh. Polyethylene glycol 6000 (BASF, Germany), polyvinyl pyrrolidone K30 (BASF, Germany), poloxamer 237 (BASF, Germany), and sodium carboxymethyl cellulose (BASF, Germany) were purchased from authorized suppliers. All chemicals and reagents were of analytical grade.

\section{Preparation of solid dispersions of ibuprofen by melting solvent method}

Polymers selection by determining saturation solubility. Physical mixtures of ibuprofen and polymers of each of $200 \mathrm{mg}$ were added to $10 \mathrm{ml}$ distilled water (Table 1). The mixtures were shake intermittently by automatic shaker (Heidolph, Germany) for 48 hours at $100 \mathrm{rpm}$ with $37^{\circ} \mathrm{C}$ temperature and then kept in static equilibrium condition for 24 hours. Finally, the preparations were centrifuged (Digisystem, Taiwan) at $5000 \mathrm{rpm}$ for 30 minutes and the supernatants were collected, which were filtered and analyzed by UV/Vis spectrophotometer at $221 \mathrm{~nm}$. The polymers which showed improved saturation solubility with ibuprofen were selected for solid dispersion preparations.

Preparation of solid dispersions of ibuprofen. Saturation solubility study showed that physical mixtures of PVP K30, poloxamer 237, and Na-CMC with ibuprofen had improved solubility rate in aqueous medium (Table 2). These three polymers were used to prepare solid dispersions of ibuprofen in PEG 6000 by melting solvent method where amount of PEG 6000 were gradually increased (Table 3). In this method, PEG 6000 was melted at $55^{\circ} \mathrm{C}$ in a hot water bath and ibuprofen was then added followed by polymer with continuous stirring to ensure homogenous mixing. Molten mixtures were cooled in an ice water bath and dried to get solid dispersions. Beside solid dispersion preparations, physical mixtures of ibuprofen with polymers and PEG 6000 were prepared using the ratio mentioned in table 3 . Then, saturation solubility of solid dispersions and physical mixtures were determined. Again, solid dispersions of ibuprofen with selected polymers in PEG 6000 were prepared where ratios of polymers to PEG 6000 were gradually increased but total amount of preparations were unchanged (Table 4). Finally, the prepared solid dispersions were dried and analyzed for different physicochemical parameters.

\section{Characterization of solid dispersions}

Determination of yield value and percent drug loading. The yield and percent drug loading were determined from the following equation. To determine percent drug loading, $10 \mathrm{mg}$ of solid dispersion from each formulation was dissolved in 10 $\mathrm{ml}$ of ethanol and adjusted to $100 \mathrm{ml}$ with water. Then absorbance of these preparations was obtained using UV/Vis spectrophotometer. Finally practical 
drug loading of individual solid dispersion was calculated from standard equation of $\mathrm{y}=0.042 \mathrm{x}$ +0.005 .

Fourier-transform infrared spectroscopic (FTIR) analysis. Solid dispersions of ibuprofen were analyzed by FTIR spectroscopy (Shimadzu, Japan). $\mathrm{KBr}$ discs of solid dispersions with ibuprofen were prepared and scanned over the frequency range 4000 to $400 \mathrm{~cm}^{-1}$.

Table 1. Physical mixtures of ibuprofen and polymers to determine saturation solubility.

\begin{tabular}{|c|c|c|c|c|c|c|c|c|c|c|c|c|}
\hline & * no. & $\mathrm{F}-1$ & F-2 & $\mathrm{F}-3$ & F-4 & F-5 & F-6 & F-7 & $\mathrm{F}-8$ & F-9 & F-10 & $\mathrm{F}-11$ \\
\hline \multicolumn{2}{|c|}{ Ibuprofen (mg) } & 200 & 200 & 200 & 200 & 200 & 200 & 200 & 200 & 200 & 200 & 200 \\
\hline \multirow{11}{*}{$\begin{array}{l}\text { Polymers } \\
\text { (mg) }\end{array}$} & PVP K30 & 200 & & & & & & & & & & \\
\hline & Cross PVP & & 200 & & & & & & & & & \\
\hline & Poloxamer 407 & & & 200 & & & & & & & & \\
\hline & Poloxamer 237 & & & & 200 & & & & & & & \\
\hline & HPMC ASLF & & & & & 200 & & & & & & \\
\hline & HPMC $5 \mathrm{cps}$ & & & & & & 200 & & & & & \\
\hline & Preg. Starch & & & & & & & 200 & & & & \\
\hline & $\mathrm{Na}-\mathrm{CMC}$ & & & & & & & & 200 & & & \\
\hline & Kollidon 90F & & & & & & & & & 200 & & \\
\hline & Kollicoat IR & & & & & & & & & & 200 & \\
\hline & Eudragit L100 & & & & & & & & & & & 200 \\
\hline
\end{tabular}

*F=Formulation

Table 2. Saturation solubility of ibuprofen from physical mixtures of ibuprofen and polymers in distilled water.

\begin{tabular}{lccccccccccc}
\hline F* no. & F-1 & F-2 & F-3 & F-4 & F-5 & F-6 & F-7 & F-8 & F-9 & F-10 & F-11 \\
\hline Saturation & 118.22 & 85.01 & 98.35 & 112.69 & 100.54 & 78.36 & 64.58 & 121.24 & 97.28 & 46.97 & 54.58 \\
solubility & \pm 0.19 & \pm 0.24 & \pm 0.21 & \pm 0.22 & \pm 0.37 & \pm 08 & \pm 0.33 & \pm 0.52 & \pm 0.49 & \pm 0.34 & \pm 0.14 \\
$(\mu \mathrm{g} / \mathrm{ml})$ & & & & & & & & & & &
\end{tabular}

*F=Formulation

Table 3. Solid dispersions of ibuprofen (IBU) with polymers in PEG 6000 where amount of PEG 6000 were gradually increased.

\begin{tabular}{|c|c|c|c|c|c|c|c|c|c|c|c|}
\hline $\begin{array}{l}\mathrm{F}^{*} \\
\text { no. }\end{array}$ & $\begin{array}{l}\text { IBU } \\
(\mathrm{mg})\end{array}$ & $\begin{array}{l}\text { PEG } \\
6000 \\
(\mathrm{mg})\end{array}$ & $\begin{array}{l}\text { PVP K30 } \\
\quad(\mathrm{mg})\end{array}$ & $\begin{array}{l}\mathrm{F}^{*} \\
\text { no. }\end{array}$ & $\begin{array}{l}\text { IBU } \\
(\mathrm{mg})\end{array}$ & $\begin{array}{l}\text { PEG } \\
6000 \\
(\mathrm{mg})\end{array}$ & $\begin{array}{c}\text { Poloxamer } 237 \\
\text { (mg) }\end{array}$ & $\begin{array}{l}\mathrm{F}^{*} \\
\text { no. }\end{array}$ & $\begin{array}{l}\text { IBU } \\
(\mathrm{mg})\end{array}$ & $\begin{array}{l}\text { PEG } 6000 \\
(\mathrm{mg})\end{array}$ & $\begin{array}{c}\mathrm{Na}-\mathrm{CMC} \\
(\mathrm{mg})\end{array}$ \\
\hline F-12 & 200 & 700 & 100 & F-16 & 200 & 700 & 100 & F-20 & 200 & 700 & 100 \\
\hline F-13 & 200 & 1100 & 100 & F-17 & 200 & 1100 & 100 & $\mathrm{~F}-21$ & 200 & 1100 & 100 \\
\hline F-14 & 200 & 1500 & 100 & F-18 & 200 & 1500 & 100 & $\mathrm{~F}-22$ & 200 & 1500 & 100 \\
\hline F-15 & 200 & 1900 & 100 & F-19 & 200 & 1900 & 100 & $\mathrm{~F}-23$ & 200 & 1900 & 100 \\
\hline
\end{tabular}

$* \mathrm{~F}=$ Formulation

Yield $=\frac{\text { Practical weight }}{\text { Theoretical weight }} \quad \times 100 \%$

Percent drug load $=\frac{\text { Practical drug load }}{\text { Theoretical drug load }} \times 100 \%$
Differential scanning calorimetric (DSC) analysis. The DSC analysis was carried out for optimized formulations and ibuprofen by using DSC (Shimadzu, Japan). Samples (2-5 mg) were heated from 30 to $300^{\circ} \mathrm{C}$ in sealed aluminum pans at scanning rate of $10^{\circ} \mathrm{C} / \mathrm{min}$ under nitrogen flow rate of 
$20 \mathrm{ml} / \mathrm{min}$. Empty aluminum pan was used as reference.

Scanning electron microscopic (SEM) analysis. The surface morphology of ibuprofen and solid dispersions were characterized by scanning electron microscopy (SEM-JEOL JSM-6490LA, Japan). The samples were built up on double-sided adhesive tapes that have previously been secured on aluminum stubs. The acceleration voltage was 20 $\mathrm{KV}$. The samples were analyzed at magnification of 500x, 1000x, 2000x, and 9000x.

Particle size analysis. The particle size of solid dispersions were measured by master sizer (NanoZS-900, England). Liquid suspension of $10 \mathrm{mg}$ from solid dispersion was prepared by $10 \mathrm{ml}$ distilled water and sonicated for 5 minutes. The result of particle size analysis was generated in terms of intensity, number and volume.

\section{RESULTS AND DISCUSSION}

\section{Preparation of solid dispersions of ibuprofen by melting solvent method}

Physical mixtures of ibuprofen with polymers at ratio of 1:1 showed different saturation solubility in distilled water (Table 2). Ibuprofen with each of PVP K30, poloxamer 237, and Na-CMC had improved solubility rate of $118.22 \pm 0.19,112.69 \pm 0.22$ and $121.24 \pm 0.52 \mu \mathrm{g} / \mathrm{ml}$, respectively. These three polymers were selected for solid dispersions of ibuprofen in PEG 6000, where the amount of PEG 6000 to polymers were gradually increased. Along with solid dispersions, physical mixtures of these ratios were prepared to analyze saturation solubility. The results showed that solid dispersions had better solubility rate than physical mixtures (Table 5). Greater saturation solubility was achieved from solid dispersions with each polymer of PVP K30, poloxamer 237, Na-CMC at ratios of 2:15:1 and 2:19:1 respectively (Table 5). But, the ratio of 2:15:1 was selected because PEG 6000 showed laxative effects in excess amount. ${ }^{18}$ Again, solid dispersions of ibuprofen were prepared by gradually increasing the amount of polymers while keeping the total amount of preparations unchanged. Among 18 preparations,
F-29, F-35, and F-41 showed better improvement of solubility rate of $952.73 \pm 1.31,878.18 \pm 0.97$ and $1263.64 \pm 1.58 \mu \mathrm{g} / \mathrm{ml}$, respectively (Table 6). The study revealed that increment of polymers in solid dispersions improved solubility profile of ibuprofen then increment of PEG 6000 in formulations.

\section{Characterization of solid dispersion preparations}

Determination of yield value and percent drug loading. Yield value and percent drug loading for F24 to F-41 were determined (Table 7). Solid dispersions of F-29, F-35, and F-41 showed maximum yield values of $74.65 \pm 0.5,91.02 \pm 0.61$, $55.55 \pm 0.35 \%$ and percent drug loading of $97.23 \pm$ $0.22,93.31 \pm 0.19,95.27 \pm 0.72 \%$, respectively. The results indicated that solid dispersions of ibuprofen in PEG 6000 with polymers at ratio of 2:9:7 provided maximum amount of drug after solidification of preparations.

Fourier-transform infrared spectroscopy (FTIR) study. FTIR spectrum of pure ibuprofen showed characteristic absorption band at $1722 \mathrm{~cm}^{-1}$ (stretching vibration of $\mathrm{C}=\mathrm{O}$ ) and $3456 \mathrm{~cm}^{-1}$ (stretching vibration of $\mathrm{O}-\mathrm{H}$ ). Similar characteristics were observed for solid dispersions at ratio of 2:9:7 with decreased peak height (Figure 1). Decrease in peak height of solid dispersions occurred due to the change of crystalline form of ibuprofen to amorphous form. These spectra did not show any significant alteration in peak area which indicated that no chemical interactions took place in solid dispersions.

Scanning electron microscopic (SEM) analysis. Scanning electron monograph of ibuprofen showed crystalline structure with different size and irregular shape (Figure 2). On the other hand, solid dispersions of ibuprofen with polymers in PEG 6000 had uniform and smooth scaly surface. This indicated that ibuprofen was properly adsorbed in PEG 6000 and homogeneously dispersed into polymers. The SEM analysis revealed that surface properties of PEG 6000 and ibuprofen were lost during melting and solidification, which indicated formation of effective solid dispersion preparations. 
Table 4. Solid dispersions of ibuprofen with polymers in PEG 6000 where amount of polymers to PEG 6000 were gradually increased.

\begin{tabular}{lccccccccccc}
\hline $\begin{array}{l}\text { F* } \\
\text { no. }\end{array}$ & $\begin{array}{l}\text { IBU } \\
(\mathrm{mg})\end{array}$ & $\begin{array}{l}\text { PEG } \\
6000 \\
(\mathrm{mg})\end{array}$ & $\begin{array}{l}\text { PVP } \\
\text { K30 } \\
(\mathrm{mg})\end{array}$ & $\begin{array}{c}\text { F* } \\
\text { no. }\end{array}$ & $\begin{array}{c}\text { IBU } \\
(\mathrm{mg})\end{array}$ & $\begin{array}{c}\text { PEG } \\
6000 \\
(\mathrm{mg})\end{array}$ & $\begin{array}{c}\text { Poloxamer } \\
237 \\
(\mathrm{mg})\end{array}$ & $\begin{array}{c}\mathrm{F}^{*} \\
\text { no. }\end{array}$ & $\begin{array}{c}\text { IBU } \\
(\mathrm{mg})\end{array}$ & $\begin{array}{c}\text { PEG } \\
6000 \\
(\mathrm{mg})\end{array}$ & $\begin{array}{c}\text { Na- } \\
\text { CMC } \\
(\mathrm{mg})\end{array}$ \\
\hline F-24 & 200 & 1400 & 200 & F-30 & 200 & 1400 & 200 & F-36 & 200 & 1400 & 200 \\
F-25 & 200 & 1300 & 300 & F-31 & 200 & 1300 & 300 & F-37 & 200 & 1300 & 300 \\
F-26 & 200 & 1200 & 400 & F-32 & 200 & 1200 & 400 & F-38 & 200 & 1200 & 400 \\
F-27 & 200 & 1100 & 500 & F-33 & 200 & 1100 & 500 & F-39 & 200 & 1100 & 500 \\
F-28 & 200 & 1000 & 600 & F-34 & 200 & 1000 & 600 & F-40 & 200 & 1000 & 600 \\
F-29 & 200 & 900 & 700 & F-35 & 200 & 900 & 700 & F-41 & 200 & 900 & 700 \\
\hline
\end{tabular}

*F=Formulation

Table 5. Saturation solubility of ibuprofen in physical mixtures and solid dispersions where amount of PEG 6000 were gradually increased.

\begin{tabular}{|c|c|c|c|c|c|c|c|c|c|c|c|c|}
\hline $\mathrm{F}^{*}$ no. & $\mathrm{F}-12$ & F-13 & F-14 & $\mathrm{F}-15$ & F-16 & F-17 & F-18 & F-19 & F-20 & $\mathrm{F}-21$ & $\mathrm{~F}-22$ & F-23 \\
\hline $\begin{array}{l}\text { Saturation } \\
\text { solubility of } \\
\text { physical } \\
\text { mixture } \\
(\mu \mathrm{g} / \mathrm{ml})\end{array}$ & $\begin{array}{l}110.47 \\
\pm 0.91\end{array}$ & $\begin{array}{l}153.32 \\
\pm 0.52\end{array}$ & $\begin{array}{l}201.22 \\
\pm 0.38\end{array}$ & $\begin{array}{l}210.03 \\
\pm 0.87\end{array}$ & $\begin{array}{l}192.97 \\
\pm 0.34\end{array}$ & $\begin{array}{l}202.05 \\
\pm 0.21\end{array}$ & $\begin{array}{l}220.71 \\
\pm 0.33\end{array}$ & $\begin{array}{l}229.54 \\
\pm 0.51\end{array}$ & $\begin{array}{l}220.00 \\
\pm 0.46\end{array}$ & $\begin{array}{l}247.27 \\
\pm 0.61\end{array}$ & $\begin{array}{l}252.73 \\
\pm 0.73\end{array}$ & $\begin{array}{l}255.64 \\
\pm 0.58\end{array}$ \\
\hline $\begin{array}{l}\text { Saturation } \\
\text { solubility of } \\
\text { solid } \\
\text { dispersion } \\
(\mu \mathrm{g} / \mathrm{ml})\end{array}$ & $\begin{array}{l}183.64 \\
\pm 0.76\end{array}$ & $\begin{array}{l}203.64 \\
\pm 0.37\end{array}$ & $\begin{array}{l}290.00 \\
\pm 0.44\end{array}$ & $\begin{array}{l}292.20 \\
\pm 0.56\end{array}$ & $\begin{array}{l}242.73 \\
\pm 0.82\end{array}$ & $\begin{array}{l}259.09 \\
\pm 0.44\end{array}$ & $\begin{array}{l}272.73 \\
\pm 0.78\end{array}$ & $\begin{array}{l}273.64 \\
\pm 0.19\end{array}$ & $\begin{array}{l}381.82 \\
\pm 0.94\end{array}$ & $\begin{array}{l}396.36 \\
\pm 0.38\end{array}$ & $\begin{array}{l}407.27 \\
\pm 0.77\end{array}$ & $\begin{array}{l}409.73 \\
\pm 0.28\end{array}$ \\
\hline
\end{tabular}

Table 6. Saturation solubility of ibuprofen in solid dispersions where amount of polymers to PEG 6000 were gradually increased.

\begin{tabular}{|c|c|c|c|c|c|}
\hline \multicolumn{6}{|c|}{ Saturation solubility of solid dispersions $(\mu \mathrm{g} / \mathrm{ml})$} \\
\hline $\mathrm{F}-24$ & $356.36 \pm 0.98$ & $\mathrm{~F}-30$ & $318.18 \pm 1.11$ & $\mathrm{~F}-36$ & $672.73 \pm 0.88$ \\
\hline $\mathrm{F}-25$ & $540.00 \pm 1.02$ & F-31 & $420.00 \pm 0.89$ & $\mathrm{~F}-37$ & $1138.18 \pm 0.69$ \\
\hline F-26 & $612.73 \pm 0.87$ & $\mathrm{~F}-32$ & $543.64 \pm 1.52$ & $\mathrm{~F}-38$ & $1190.91 \pm 1.28$ \\
\hline $\mathrm{F}-27$ & $618.18 \pm 1.23$ & $\mathrm{~F}-33$ & $650.91 \pm 1.37$ & F-39 & $1210.91 \pm 1.51$ \\
\hline F-28 & $716.36 \pm 1.05$ & $\mathrm{~F}-34$ & $827.27 \pm 1.28$ & $\mathrm{~F}-40$ & $1249.09 \pm 0.97$ \\
\hline F-29 & $952.73 \pm 1.31$ & F-35 & $878.18 \pm 0.97$ & F-41 & $1263.64 \pm 1.58$ \\
\hline
\end{tabular}

Table 7. Yield value and percent drug loading in solid dispersions of ibuprofen.

\begin{tabular}{ccccccccc}
\hline F* no. & $\begin{array}{c}\text { Yield value } \\
(\%)\end{array}$ & $\begin{array}{c}\text { Percent drug } \\
\text { loading }\end{array}$ & F*no. & $\begin{array}{c}\text { Yield value } \\
(\%)\end{array}$ & $\begin{array}{c}\text { Percent drug } \\
\text { loading }\end{array}$ & $\begin{array}{c}\text { F* no. } \\
\text { n }\end{array}$ & $\begin{array}{c}\text { Yield value } \\
(\%)\end{array}$ & $\begin{array}{c}\text { Percent drug } \\
\text { loading }\end{array}$ \\
\hline F-24 & $63.02 \pm 0.38$ & $75.21 \pm 0.63$ & F-30 & $76.13 \pm 0.97$ & $91.41 \pm 0.52$ & F-36 & $47.27 \pm 0.19$ & $92.64 \pm 0.97$ \\
F-25 & $65.35 \pm 0.41$ & $78.56 \pm 0.27$ & F-31 & $78.15 \pm 0.88$ & $89.46 \pm 0.71$ & F-37 & $52.89 \pm 0.38$ & $94.25 \pm 0.88$ \\
F-26 & $62.54 \pm 0.29$ & $82.32 \pm 0.45$ & F-32 & $87.52 \pm 0.59$ & $90.66 \pm 0.68$ & F-38 & $49.26 \pm 0.72$ & $92.76 \pm 0.58$ \\
F-27 & $69.73 \pm 0.42$ & $87.54 \pm 0.61$ & F-33 & $86.65 \pm 0.36$ & $92.78 \pm 0.27$ & F-39 & $51.34 \pm 0.56$ & $95.23 \pm 0.47$ \\
F-28 & $72.27 \pm 0.33$ & $91.98 \pm 0.37$ & F-34 & $87.27 \pm 0.35$ & $92.33 \pm 0.55$ & F-40 & $53.73 \pm 0.61$ & $93.64 \pm 0.84$ \\
F-29 & $74.65 \pm 0.51$ & $97.23 \pm 0.22$ & F-35 & $91.02 \pm 0.61$ & $93.31 \pm 0.19$ & F-41 & $55.55 \pm 0.35$ & $95.27 \pm 0.72$ \\
\hline
\end{tabular}

*F=Formulation 
Differential scanning calorimetric (DSC) analysis. The DSC thermograms of ibuprofen and PEG 6000 showed endothermic melting point at $75.91^{\circ} \mathrm{C}$ and $63.07^{\circ} \mathrm{C}$ with sharp peaks (Figure 3). Solid dispersions of ibuprofen in PEG 6000 with each of PVP K30, poloxamer 237, and Na-CMC at ratio of 2:9:7 demonstrated lower melting point of $57.75^{\circ} \mathrm{C}, 58.79^{\circ} \mathrm{C}$, and $59.59^{\circ} \mathrm{C}$, respectively where sharp peaks were disappeared. All thermogrms showed shifting of endothermic peaks to lower temperature than the crystalline drug. Shifting of melting point of solid dispersions towards lower temperature than pure drug indicated physical interaction between drug and polymers. ${ }^{19}$ In solid dispersion, if a crystalline drug is soluble in molten hydrophilic carrier at the melting temperature of the carrier or vice versa, then the dispersion could be eutectic. $^{20}$ The eutectic mixtures of ibuprofen and polymers exhibit complete miscibility in liquid state where the drug-polymers physical interactions took place. But after solidification, ibuprofen and polymers completely separated from each other due to lattice mismatch where the physical interactions would be negligible. ${ }^{17,18}$

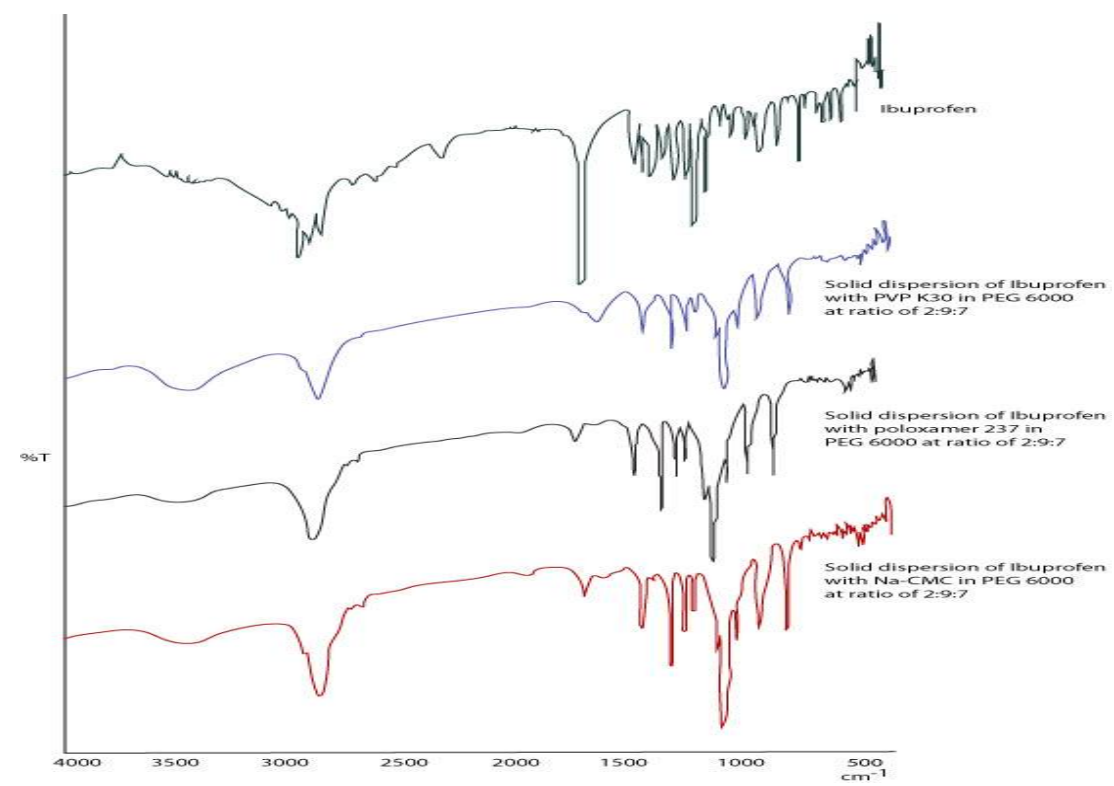

Figure 1. FTIR spectrum for solid dispersions of ibuprofen in PEG 6000 with each of PVP K30, poloxamer 237, and NaCMC at ratio of 2:9:7.
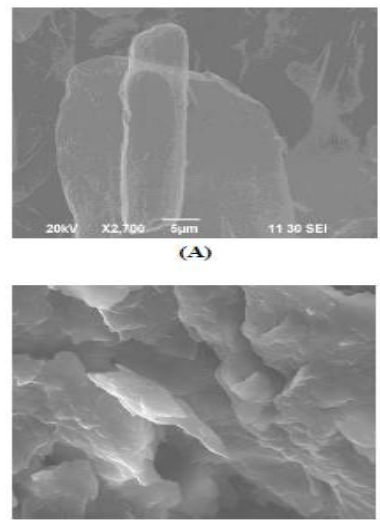

(C)

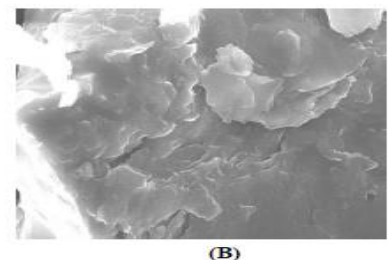

(B)

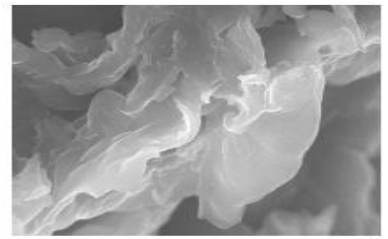

(D)

Figure 2. Scanning electron microscopic monogram of pure ibuprofen (A), solid dispersion of ibuprofen in PEG 6000 with each of PVP K30 (B), poloxamer 237 (C), and Na-CMC (D) at ratio of 2:9:7. 


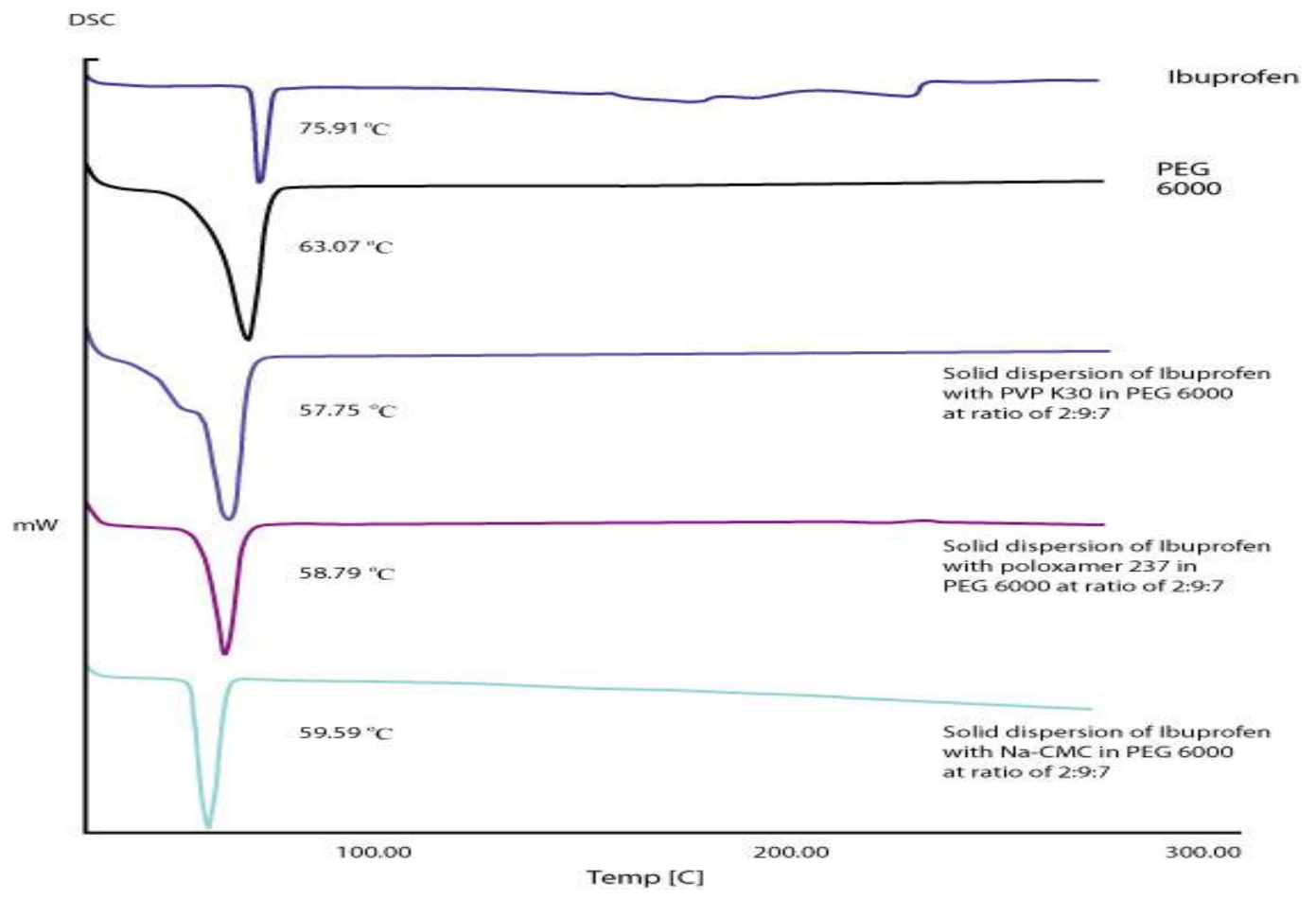

Figure 3. DSC thermograms of ibuprofen, PEG 6000, and solid dispersions of ibuprofen in PEG 6000 with polymers at ratio of 2:9:7.

Particle size distribution analysis. Pure ibuprofen had particle size distribution of $32.23 \pm$ $0.11 \mu \mathrm{m}$ where solid dispersions of drug and polymers at ratio of 2:9:7 showed significant reduction in particle size of $18.81 \pm 0.19,30.11 \pm$ 0.08 and $45.21 \pm 0.13 \mathrm{~nm}$, respectively. According to Tamman's rule, PEG-ibuprofen eutectic mixtures might have well defined microstructure with a reduction in drug particle size that have an important role for enhancement of dissolution rate. ${ }^{7,13}$

\section{CONCLUSION}

The study showed that solid dispersion technique can be used to improve aqueous solubility of ibuprofen to a great extent. Better aqueous solubility was obtained from solid dispersions of ibuprofen in PEG 6000 with each of PVP K30, poloxamer 237, and Na-CMC at ratio of 2:9:7. Physicochemical properties of these preparations were ascertained by FTIR, DSC, SEM, and particle size analyses, which revealed good compatibility between drug and polymers. The results from the present study suggested that solid dispersions of ibuprofen with each of PVP K30, poloxamer 237, and Na-CMC may be a promising approach to improve its solubility as well as bioavailability.

\section{REFERENCES}

1. Chiou, W.L. and Riegelman, S. 1971. Pharmaceutical application of solid dispersion systems. J. Pharm. Sci. 73, 1281-1303.

2. Craig, D.Q.M. 2002. The mechanism of drug release from solid dispersion in water-soluble polymers. Int. J. Pharm. 231, 131-144.

3. Taylor, L.S. and Zografi, G. 1997. Spectroscopic characterization interactions between PVP and indomethacin in amorphous molecular dispersions. Pharm. Res. 14, 16911698.

4. Dittgen, M., Fricke, S., Gerecke, H. and Osterwald, H. 1995. Hot spin mixing: a new technology to manufacture solid dispersions of testosterone. Pharmazie 50, 225-236.

5. Newa, M., Bhandari, K.H., Li, D.X., Kim, J.O, Yoo, D.S., Kim, J.A., Yoo, B.K., Woo, J.S., Lyoo, W.S., Yong, C.S. and Choi, H.G. 2008. Preparation and evaluation of immediate release ibuprofen solid dispersions using polyethylene glycol 4000. Biol. Pharm. Bull. 31, 939-945. 
6. Newa, M., Bhandari, K.H., Li, D.X., Kwon, T.H., Kim, J.A. Yoo, B.K., Woo, J.S., Lyoo, W.S., Yong, C.S. and Choi, H.G. 2007. Preparation, characterization and in vivo evaluation of ibuprofen binary solid dispersion with poloxamer 188. Int. J. Pharm. 243, 228-237.

7. Seo, A., Holm, P., Kristensen, H.G. and Schaefer, T. 2003. The preparation of agglomerates containing solid dispersions of diazepam by melt agglomeration in a high shear mixer. Int. J. Pharm. 259, 161-171.

8. Vilhelmsen, T., Eliasen, H. and Schaefer, T. 2005. Effect of a melt agglomeration process on agglomerates containing solid dispersions. Int. J. Pharm. 303, 132-142.

9. Covadonga, A., Ignacio, N., Juan, J.T., John, G., Henrike, P. and Alfredo, G. 2011. Investigation on the possibility of biowaivers for ibuprofen. J. Pharm. Sci. 100, 2343-2349.

10. Laska, E.M., Sunshine, A., Marrero, I., Olson, N., Siegel, C. and Mc-Cormick, N. 1986. The correlation between blood levels of ibuprofen and clinical analgesic response. Clin. Pharmacol. Ther. 40, 1-7.

11. Bogdan, T., Adriana, F., Geza, B., Gerlinde, R. and Dumitru, T. 2010. Thermal stability of Ibuprofen: kinetic study under non-isothermal conditions. Rev. Roum. Chim. 55, 553-558.

12. Serajuddin, A.T.M. 1999. Solid dispersion of poorly water soluble drugs: early promises, subsequent problems, and recent breakthroughs. J. Pharm. Sci. 88, 1058-1066.

13. Passerini, N., Gonzalez, R.M.L., Cavallari, C., Rodriguez, L. and Albertini, B. 2002. Preparation and characterization of ibuprofen-poloxamer 188 granules obtained by melt granulation. Eur. J. Pharm. Sci. 15, 71-78.
14. Craig, D.Q.M. 1990. Polyethyelene glycols and drug release. Drug Dev. Ind. Pharm. 16, 2501-2506.

15. Mura, P., Manderioli, A., Bramanti, G. and Ceccarelli, L. 1996. Properties of solid dispersions of naproxen in various polyethylene glycols. Drug Dev. Ind. Pharm. 22, 909-916.

16. Madhuri, N., Krishna, H.B., Jung, A.K., Bong, K.Y., Han, G.C., Chul, S.Y., Jong, S.W. and Won, S.L. 2008. Preparation and evaluation of fast dissolving ibuprofenpolyethylene glycol 6000 solid dispersions. Drug Deliver. 15, 355-364.

17. Nakamichi, K., Nakano, T., Yasuura, H., Izumi, S. and Kawashima, Y. 2002. The role of the kneading paddle and the effects of screw revolution speed and water content on the preparation of solid dispersions using a twin-screw extruder. Int. J. Pharm. 241, 203-211.

18. Manhal, I., Anju, M., Erin, L. and Sury, A. 2016. Review of efficacy and safety of laxatives use in geriatrics, World $J$. Gastrointest. Pharmacol. Ther. 7, 334-342.

19. Madhuri, N., Krishna, H.B., Jong, O.K., Jong, S.I., Jung, A.K., Bong, K.Y., Jong, S.W., Han, G.C. and Chul, S.Y. 2008. Enhancement of solubility, dissolution and bioavailability of ibuprofen in solid dispersion systems. Chem. Pharm. Bull. 56, 569-574.

20. Carstensen, J.T. 2001. Melting point diagrams and eutectics in advanced pharmaceutical solids, Marcel Dekker Inc., New York, pp. 170-189. 